\title{
Pulsed-wave tissue Doppler imaging of the myocardium of cats with induced thyrotoxicosis
}

\author{
Doppler tecidual pulsado do miocárdio de gatos com tirotoxicose induzida
}

\author{
Daniel Capucho de Oliveira ${ }^{\mathrm{I}^{*}}$ Daniel Cometti Borlini ${ }^{\mathrm{I}}$ Warley Gomes dos Santos ${ }^{\mathrm{I}}$ \\ Jessica Nascimento Moraes Monteiro ${ }^{\mathrm{I}}$ Lorena Adão Vescovi Séllos Costa \\ Aloir Queiroz Araújo SobrinhoiI Fabiano Séllos Costa ${ }^{\mathrm{I}}$
}

\begin{abstract}
Left ventricular myocardial motion was quantified using pulsed-wave tissue Doppler imaging ( $P W-T D I)$ in nine adult cats before and after thyrotoxicosis induction. In order to induce thyrotoxicosis, all cats were given $150 \mu \mathrm{g} \mathrm{kg}^{-1}$ of levothyroxine sodium as a single oral dose each day for 10 weeks. PW-TDI examinations were performed immediately before the induction and by the end of the experimental protocol. An increase in myocardial motion velocity was documented at the interventricular septum level, demonstrated by an elevation in systolic ( $\mathrm{Sa}$ ), and early (Ea) and late (Aa) diastolic waves $(P<0.05)$. However, no alteration in $S a, E a$ and Aa values was seen at the lateral mitral annulus. Heart rate increased significantly between the experimental stages, and three of the animals presented fused Ea and Aa waves at the end of the experiment. The experimental protocol used in this study caused alterations in left ventricular myocardial motion velocity, but did not impair left ventricular diastolic function.
\end{abstract}

Key words: cat, echocardiography, hyperthyroidism, tissue Doppler imaging.

\section{RESUMO}

A velocidade de movimentação miocárdica do ventrículo esquerdo foi quantificada por meio de exames ecocardiográficos com Doppler tecidual pulsado (PW-TDI) em nove gatos adultos antes e após indução à tirotoxicose. Para indução da tirotoxicose, todos os gatos receberam doses diárias de $150 \mathrm{mg} \mathrm{kg}^{-1}$ de levotiroxina sódica, por via oral, durante 10 semanas. Os exames de PW-TDI foram realizados imediatamente antes da indução e ao final do protocolo experimental. Uma elevação na velocidade de movimentação

\begin{abstract}
miocárdica foi documentada ao nível do septo interventricular, demonstrado por um aumento das ondas sistólica (Sa) e diastólicas (Ea e Aa; $\mathrm{P}<0,05)$. No entanto, nenhuma alteração nos valores de Sa, Ea e Aa foi encontrada ao nível da parede livre do ventrículo esquerdo. A frequência cardiaca aumentou significativamente entre os momentos experimentais, sendo que três animais apresentaram fusão das ondas Aa e Ea ao final do experimento. O protocolo experimental utilizado neste estudo causou alterações na velocidade de movimentação do miocárdio ventricular esquerdo, mas sem causar danos à função diastólica do ventrículo esquerdo.
\end{abstract}

Palavras-chave: gato, ecocardiografia, hipertiroidismo, Doppler tecidual.

\section{INTRODUCTION}

Hyperthyroidism is a multisystemic clinical alteration resulting from excessive concentrations of thyroid hormones and is considered the endocrine disease of highest incidence among domestic felines in North America (MOONEY, 2005). The prevalence of this disease in Brazil's feline population is unknown (CUNHA et al., 2008). Hyperthyroidism commonly induces cardiovascular alterations in humans and animals, such as cardiac arrhythmias, left ventricular hypertrophy, diastolic dysfunction and enhancement in systolic function (BOND et al., 1988; KAHALY \& DILLMANN, 2005; SYME, 2007).

'Departamento de Medicina Veterinária, Centro de Ciências Agrárias (CCA), Universidade Federal do Espírito Santo (UFES), 29500-000, Alegre, ES, Brasil. E-mail: danielcapucho@gmail.com. *Autor para correspodência.

"Departamento de Ecocardiografia, Hospital Universitário Cassiano Antônio de Moraes (HUCAM), Universidade Federal do Espírito Santo (UFES), Vitória, ES, Brasil. 
The ancillary exams are of great value for the investigation of the cardiovascular system, helping the clinician to reach a conclusive diagnosis and monitor the progress of patients. In feline hyperthyroidism, certain studies demonstrate the importance of the echocardiography for the characterization of alterations secondary to thyrotoxicosis, since it is a non-invasive exam capable of assessing cardiac function parameters (BOND et al., 1988; KIENLE et al., 1997).

Conventional Doppler techniques allow the study of blood flow direction and velocity at anatomical key points, besides detecting the presence of turbulent flows in the heart and in the large vessels (BONAGURA et al., 1998; BOON, 1998). Tissue Doppler imaging (TDI) is a relatively new technique that allows a quantitative evaluation of the myocardial motion velocity, in both systole and diastole (SIMPSOM et al., 2009). The use of TDI, in comparison with the bi-dimensional echocardiography and conventional Doppler, provides a better evaluation of myocardial segmental function, as well as allows an adequate evaluation of cardiac diastolic function (SOHN et al., 1997), besides revealing with greater precision, sudden changes in cardiac contractility, which are undetectable in conventional echocardiography (CHETBOUL et al., 2006).

The aim of our study was to determine if the elevation of the serum levels of the thyroid hormones would increase left ventricular myocardial motion velocities in cats by using pulsed-wave TDI technique (PW-TDI).

\section{MATERIALS AND METHODS}

In order to choose the experimental group, selection exams were performed, which involved a detailed clinical evaluation, echocardiography, electrocardiography, systolic arterial blood pressure and thoracic radiographies, as well as complete blood counts, urine analyses and the dosage of glutamicpyruvate transaminase (GPT), glutamic oxaloacetic transaminase (GOT), alkaline phosphatase (ALP), gammaglutamyl transferase (GGT), blood urea, creatinine, total protein, albumin and total T4 serum levels.

Nine non-neutered/non-spayed young mixed-breed cats (five male and four female), with a mean age of $36 \pm 6$ months (range $30-48$ months) and a mean weight of $2.7 \pm 0.9$ (range $2.1-3.9 \mathrm{~kg}$ ), were used in this study. During the experimental period, the animals were maintained in collective shelters with access to solar light, receiving water and premium dry food $a d$ libitum. All cats were given $150 \mu \mathrm{g} \mathrm{kg}^{-1}$ of levothyroxine sodium as a single oral dose each day for 10 weeks. The levothyroxine sodium dose was adjusted for changes in body weight every week. This protocol has been validated previously by demonstrating that this dose of levothyroxine induces an elevation in the serum levels of thyroid hormones, as well as clinical signs, compatible with hyperthyroidism(CARDOSO et al., 2005).

Echocardiographic examinations and total

T4 serum levels analysis were performed in two experimental stages: one before the beginning of the induction protocol (initial experimental stage - S0), and the other after 10 weeks of treatment (final experimental stage - S1). Blood samples were obtained by jugular venipuncture and immediately centrifuged. The serum levels of total T4 were measured by the technique of radioimmunoassay, and the exams were performed in duplicate .

Echocardiographic examinations were performed by the same trained observer using an ultrasound machine (b) equipped with a $6 \mathrm{MHz}$ microconvex transducer. To perform the examinations the cats were chemically restrained with $0.12 \mathrm{ml} \mathrm{kg}^{-1}$ tiletamine and zolazepam associated with $0.1 \mathrm{mg} \mathrm{kg}^{-1}$ midazolam, both injected intramuscularly.

For each echocardiographic variable, a mean of three measurements was determined from three consecutive cardiac cycles on the same frame. PWTDI measurements used to evaluate left ventricular longitudinal myocardial motion of the cats submitted to thyrotoxicosis were the values of $\mathrm{Ea}$ (early diastolic maximal velocity), Aa (late diastolic maximal velocity) and $\mathrm{Sa}$ (systolic maximal velocity), measured at the lateral and septal mitral annulus. These measurements were performed at the left apical four-chamber view (KOFFAS et al., 2006).

Ventricular measurements (short-axis view) were obtained from the right parasternal location by use of 2D-guided M-mode (BOON, 1998). Left ventricular end-diastolic and end-systolic diameters (LVDD and LVSD), left ventricle free wall thickness (LVFW), and interventricular septal thickness (IVS) in diastole and systole were measured. Left ventricular fractional shortening (FS) was calculated by the formula: [(LVDD - LVSD) / LVDD] x 100; and left ventricular ejection fraction (EF) was automatically calculated by the ultrasound unit's software. Left atrium-to-aorta ratio was calculated from a 2D short-axis view. Pulsed-wave Doppler imaging was used to determine maximal early (E) and late (A) diastolic mitral flow velocities, obtained from a left apical four-chamber view (BOON, 1998).

Statistical analysis of the variables between S0 and S1 was performed by use of computer software (c). A parametric statistical test (paired t-test) was used 
when the variables were normally distributed, and a non-parametric statistical test (Wilcoxon test) was used in the absence of normal distribution. The normality hypothesis was verified by the Shapiro-Wilk test and the indexes of asymmetry. Correlations between heart rate, total T4 serum levels, echocardiographic parameters and the myocardial velocities were examined by use of Pearson product moment correlation. The level of significance used for all the tests was of $5 \%$ $(\mathrm{P}<0.05)$.

Three weeks after the end of the experiment, with the remission of the clinical signs secondary to thyrotoxicosis, all the animals used in our study were donated for adoption.

\section{RESULTS}

In this study, all the cats presented a statistically significant elevation of total T4 serum levels at the end of the experimental protocol $(\mathrm{P}=0.0078)$. The mean values of total T4 were of $28.31 \pm 8.02 \mathrm{nmol} \mathrm{L}^{-1}$ at $\mathrm{S} 0$ and $79.02 \pm 46.51 \mathrm{nmol} \mathrm{L}^{-1}$ at S1. Clinical evaluation of the cats by the end of the experimental period allowed the characterization of clinical signs commonly observed in endogenous hyperthyroidism, such as tachycardia, weight loss, polyphagia, hyperactivity and diarrhea.

Echocardiographic examination revealed a statistically significant reduction in LVDD and LVSD, but only one of the cats $(11.1 \%)$ had these values below the reference range for the feline specie (BOON, 1998). This animal also presented an increase in LVFW and IVS thickness in both diastole and systole. EF, FS, left atrium-to-aorta ratio and mitral flow velocities did not suffer any alteration at the end of the experimental protocol. Mean heart rate during echocardiographic examination suffered a statistically significant increase between the experimental stages $\left(190 \pm 36\right.$ beats min $^{-1}$ at S0 and $219 \pm 33$ beats $\min ^{-1}$ at S1).

At S0, PW-TDI graphics provided one positive systolic wave ( $\mathrm{Sa}$ ), and two negative diastolic waves (Ea and Aa, respectively, in early and late diastole; Figure 1A). However, at S1, three (33.3\%) animals presented fused $\mathrm{Ea}$ and Aa waves, displaying a graphic with one positive wave (Sa) and one negative wave (fused Ea-Aa; Figure 1B). This fusion occurred in both lateral and septal leaflets of the mitral valve. Considering the fusion of Ea and Aa waves, at the final stage of the experiment we only took into account the values of $\mathrm{Aa}$ in the six cats without Ea-Aa fusion.

Statistical analysis of PW-TDI results obtained at $\mathrm{S} 0$ and $\mathrm{S} 1$, showed a significant increase in myocardial motion velocity at the level of the interventricular septum, demonstrated by an elevation in septal Sa, septal Ea and septal Aa values. However, no alteration in $\mathrm{Sa}$, Ea and Aa values was documented at the lateral mitral annulus (Table 1). No significant correlation was found between the serum levels of total $\mathrm{T} 4$, heart rate, echocardiographic parameters and myocardial velocities after induction of thyrotoxicosis.

\section{DISCUSSION}

The thyrotoxicosis induction protocol used in this experiment was similar to the one described by CARDOSO et al. (2005) in felines, in which the dosage
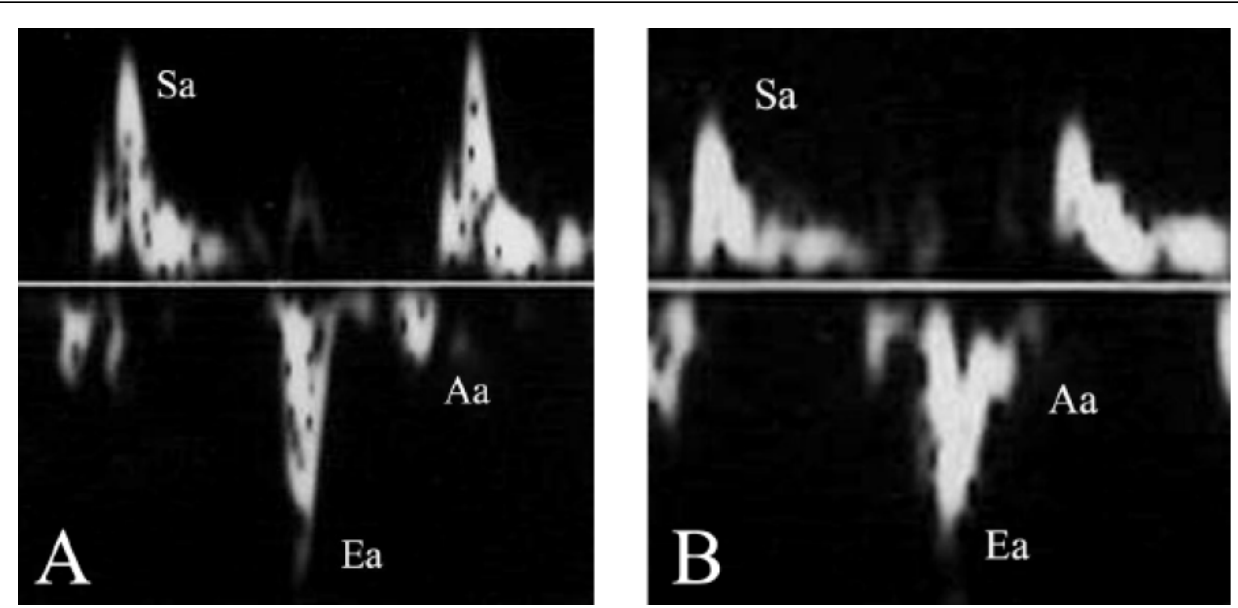

Figure 1 - Pulsed-wave tissue Doppler imaging tracing obtained from the septal mitral annulus along the longitudinal axis of one healthy cat (A) and one cat with experimental thyrotoxicosis (B). In A one positive wave $(\mathrm{Sa})$ and two negative waves (Ea and $\mathrm{Aa}$ ) can be observed in the graphic. In $\mathrm{B}$ the diastolic negative waves were fused due to tachycardia. 
Table 1 - Left ventricular myocardial motion velocities obtained through pulsed-wave tissue Doppler imaging technique in nine cats, before (S0) and after (S1) the protocol of induced thyrotoxicosis. Data are expressed as mean \pm standard deviation.

\begin{tabular}{llll}
\hline Parameters & S0 & S1 & P \\
\hline Lat Sa $\left(\mathrm{cm} \mathrm{s}^{-1}\right)$ & $8.28 \pm 1.60$ & $8.96 \pm 2.41$ & 0.5147 \\
Sep Sa $\left(\mathrm{cm} \mathrm{s}^{-1}\right)$ & $6.33 \pm 1.66$ & $10.28 \pm 4.30$ & 0.0077 \\
Lat Ea $\left(\mathrm{cm} \mathrm{s}^{-1}\right)$ & $11.96 \pm 4.05$ & $10.71 \pm 3.99$ & 0.2604 \\
Sep Ea $\left(\mathrm{cm} \mathrm{s}^{-1}\right)$ & $7.20 \pm 2.54$ & $11.97 \pm 6.86$ & 0.0209 \\
Lat Aa $\left(\mathrm{cm} \mathrm{s}^{-1}\right)$ & $6.96 \pm 3.09$ & $6.50 \pm 5.48^{*}$ & 0.6159 \\
Sep Aa $\left(\mathrm{cm} \mathrm{s}^{-1}\right)$ & $4.72 \pm 1.54$ & $7.43 \pm 2.38^{*}$ & 0.0446 \\
\hline
\end{tabular}

* These values correspond to mean \pm standard deviation of the 6 cats that did not present fused Ea-Aa waves.

S0, initial stage; S1, 10 weeks of treatment; P, significance level; lat Sa, systolic maximal velocity in lateral mitral annulus; sep Sa, systolic maximal velocity in septal mitral annulus; lat Ea, early diastolic maximal velocity in lateral mitral annulus; sep Ea, early diastolic maximal velocity in septal mitral annulus; lat Aa, late diastolic maximal velocity in lateral mitral annulus; sep Aa, late diastolic maximal velocity in septal mitral annulus.

of the serum levels of thyroid hormones demonstrated a statistically significant elevation after the first week of the experiment. Levothyroxine sodium oral administration also promoted clinical and laboratorial alterations similar to endogenous hyperthyroidism, in experimental studies with dogs and rats (ADAMS \& JOWSEY, 1966; KUNG \& NG, 1994), as well as in hypothyroid human patients with oversupplementation of levothyroxin sodium (FALLON et al., 1983).

The normal values of total T4 in cats ranges from 12.87 to $38.61 \mathrm{nmol} \mathrm{L}^{-1}$, and cats with endogenous hyperthyroidism present total T4 values between 35.9 and 693.6nmol L-1 (PETERSON, 2006). However, since the serum levels of thyroid hormones can change due to different laboratorial techniques, conclusive diagnosis of hyperthyroidism is often made by the combination of elevated total T4 serum levels with the common clinical signs of the disease (MOONEY, 2005). Thus, combining the elevation of total T4 serum levels with the results of clinical evaluations it can be assumed that the cats of our study developed a profile of induced thyrotoxicosis similar to endogenous hyperthyroidism.

Several studies in animals have demonstrated the efficiency of PW-TDI in the diagnosis of acquired and congenital cardiomyopathies in dogs and cats, through the early detection of alterations in myocardial motion (CHETBOUL et al., 2006; KOFFAS et al., 2006; MACDONALD et al., 2007). In humans, studies were conducted by using PW-TDI in patients with hyperthyroidism (SMIT et al., 2005; ARINC et al., 2006; DI BELLO et al., 2007). However, the use of this technique in cats with thyrotoxicosis is little described in the consulted literature (SIMPSON et al., 2009).

TDI is considered a technique with high repeatability and reproducibility in cats (CHETBOUL et al., 2004; KOFFAS et al., 2006). These aspects are very important because in clinical use, repeated measures are performed over the duration of the myocardial disease. Myocardial motion velocities can suffer small variations due to observer experience and the angle of the transducer during the exam (KOFFAS et al., 2006). This variation can be minimized by always having the examination performed by a single trained observer. It is also known that measurements performed at heart basis (as made in our study) have higher repeatability and reproducibility, than those obtained near heart apex (CHETBOUL et al., 2004).

KOFFAS et al. (2006) quantified myocardial motion by PW-TDI in 25 healthy cats without chemical restraint, obtaining results close to those described in this article. The proximity of the values obtained in our study with those obtained by KOFFAS et al. (2006) demonstrate that the anesthetic protocol had little influence in the PW-TDI measurements. This is in agreement with the reports of HELLYER et al. (1988), which stated that the cardiovascular effects resulting from dissociative anesthesia with tiletamine and zolazepam in cats normalize after a minute of the application.

In our study, the cats with induced thyrotoxicosis had an increase in the $\mathrm{Sa}, \mathrm{Ea}$ and $\mathrm{Aa}$ velocities measured at the interventricular septum level. Previously, hyperthyroid cats have demonstrated an increased fractional shortening, which was related to an augmented inotropic state (BOND et al., 1988). The PW-TDI analysis provided evidence for an increase in systolic function (inotropic state) at the septal level, what can be attributable to several reasons; these include either elevation in beta-adrenergic receptor density, as has already been demonstrated in cultured ventricular myocytes exposed to thyroid hormones (BAHOUTH, 1991), or an increased metabolic demand (KAHALY \& DILLMANN, 2005). In humans, 
SHAN et al. (2000) reported that PW-TDI Sa velocities are positively correlated with beta-adrenergic receptor density, and negatively correlated with interstitial fibrosis. In cats with clinical hyperthyroidism, SIMPSON et al. (2009) observed an overall elevation in Sa velocities, which was more pronounced at the septal level. The authors hypothesized that the increased Sa velocities in the hyperthyroid cats could be related to an increased beta-adrenoceptor density in the hyperthyroid state; the same probably occurred with the cats of our study. However, the interventricular septum seems to suffer a greater influence from the thyroid hormones in comparison with left ventricular free wall, as the elevation in myocardial motion velocity only occurred at the septal mitral annulus.

Secondary to the hypermetabolic state promoted by the thyrotoxicosis, it was also verified an elevation of the heart rate by the end of the experimental protocol, which caused a fusion of the diastolic waves in some of the cats. CHETBOUL et al. (2004) demonstrated that there is a positive correlation between myocardial velocity and heart rate in a population of 100 healthy cats. As their studied population was remarkably larger than ours, the elevation in the myocardial velocity observed in our experimental group may be attributable to the elevation of heart rate, even though no correlation between these parameters was observed in our study. The same authors also stated that this fusion of Ea and Aa waves observed in the final stage of our experiment is considered to be a common finding in tachycardic cats.

As observed in cats with thyrotoxicosis, the occurrence of cardiovascular alterations was also previously mentioned by ARINC et al. (2006) in humans; these authors described a positive correlation between the thyroid hormonal levels and the velocity of contraction of the right ventricular myocardium. After a comparison with healthy individuals, they verified an increase in myocardial motion velocity in hyperthyroid patients and a reduction in hypothyroid patients. In our study, no correlation was found between myocardial velocities and the serum levels of total T4. Despite the limitations imposed by the size of our studied population, this finding may suggest that the elevation in myocardial motion velocity is not fully dependent from the magnitude of the increase in the serum levels of thyroid hormones.

At the final stage of our experiment the cats with induced thyrotoxicosis had no findings compatible with diastolic dysfunction in PW-TDI results. FAZIO et al. (2004), as well as KAHALY \& DILLMANN (2005), stated that in initial cases, thyrotoxicosis can improve left ventricular diastolic function in humans. However, the same authors reported that in humans with thyrotoxicosis for prolonged periods, a decrease in left ventricular diastolic function can be verified. An impairment in left ventricular diastolic function is also observed in feline patients with hypertrophic cardiomyopathy, and results from alterations of the ventricular mass (KOFFAS et al., 2006; MACDONALD et al., 2007; SIMPSON et al., 2009). In PW-TDI, a diastolic dysfunction would cause a reduction in myocardial motion velocity during the passive filling of the left ventricle, characterized by lower Ea values at the septal and lateral edges of the mitral annulus, causing an Ea/Aa reversal (KOFFAS et al., 2006), which was not observed in our experimental group.

The use of PW-TDI has demonstrated that it is an excellent method for non-invasive analysis of the diastolic function, for being less sensitive to the interference of the preload than the measurement of the mitral flow by the conventional Doppler examination. This aspect makes its results more precise, precocious and of greater utility in the identification of diastolic dysfunction (SOHN et al., 1997; NAGUEH et al., 1997). Particularly in feline hyperthyroidism TDI is of great importance, since according to SYME (2007) hyperthyroid cats present a significant increase in preload attributable to an increase in the venous blood volume associated to a reduction in arterial volume.

\section{CONCLUSION}

The experimental protocol used in this study is responsible, within a short period of time, for causing alterations in left ventricular myocardial longitudinal motion at the interventricular septum level, but without damage to the overall diastolic function of the left ventricle.

\section{BIOETHICS AND BIOSSECURITY COMMITTEE APPROVAL}

This study is a matched-pair clinical trial approved by the Ethics and Animal Well-fare Committee of the Universidade Estadual Paulista (UNESP), Botucatu Campus, Brazil, under protocol number 49/2002-CEEA.

\section{SOURCES AND MANUFACTURERS}

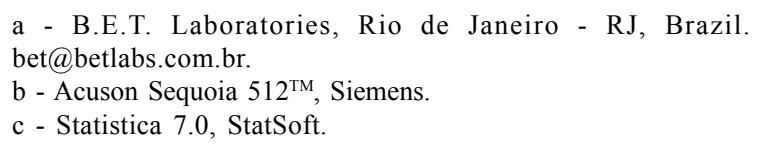

\section{REFERENCES}

ADAMS, P.; JOWSEY, J. Bone and mineral metabolism in hyperthyroidism: an experimental study. Endocrinology, v.81, p. $735-740,1966$.

Ciência Rural, v.41, n.6, jun, 2011. 
ARINC, H. et al. Evaluation of right ventricular function in patients with thyroid dysfunction. Cardiology, v.105, p.8994, 2006

BAHOUTH S.W. Thyroid hormones transcriptionally regulate the b1-qdrenergic receptor gene in cultured ventricular myocytes. Journal of Biological Chemistry, v.266, p.15863-15869, 1991 .

BONAGURA, J.D. et al. Doppler echocardiography I: pulsedwave and continuous-wave examinations. Veterinary Clinics of North America - Small Animal Practice, v.28, p.13251359,1998

BOND, B.R. et al. Echocardiographic findings in 103 cats with hyperthyroidism. Journal of the American Veterinary Medical Association, v.192, p.1546-1549, 1988.

BOON, J.A. Manual of Veterinary Echocardiography. Baltimore: Lippincott Willians \& Wilkins, 1998. 478p.

CARDOSO, M.J.L. et al. Manifestações clínicas em gatos com hipertiroidismo experimental. Archives of Veterinary Science, v.10, n.2, p.135-44, 2005.

CHETBOUL, V. et al. Quantification, repeatability, and reproducibility of feline radial and longitudinal left ventricular velocities by tissue Doppler imaging. American Journal of Veterinary Research, v.65, p.566-572, 2004.

CHETBOUL, V. et al. Two-dimensional color tissue Doppler Imaging detects myocardial dysfunction before occurrence of hypertrophy in a young Maine Coon cat. Veterinary Radiology \& Ultrasound, v.47, p.295-300, 2006.

CUNHA M.G.M.C.M. et al. Hipertireoidismo felino. Ciência Rural, v.38, p.1486-1494, 2008. Available from: <http:// ww w.s c i e 1 o.b r / s c i e 1 o.ph p ? p id = S 0103 $84782008000500050 \&$ script $=$ sci arttext $>$. Accessed: Jun 02, 2010. doi: $10.1590 / \mathrm{S} 0103-84782008000500050$.

DI BELLO, V. et al. Early abnormalities of left ventricular myocardial characteristics associated with subclinical hyperthyroidism. Journal of Endocrinological Investigation, v.30, p.564-571, 2007.

FALLON, M.D. et al. Exogenous hyperthyroidism with osteoporosis. Archives of Internal Medicine, v.143, p.442444, 1983.

FAZIO, S. et al. Effects of thyroid hormone on the cardiovascular system. Recent Progress in Hormone Research, v.59, p.3150, 2004.

HELLYER, P. et al. Cardiorespiratory effects of the intravenous administration of tiletamine-zolazepam to cats. Veterinary Surgery, v.17, n.2, p.105-109, 1988

KAHALY, G.J.; DILLMANN, W.H. Thyroid hormone action in the heart. Endocrine Reviews, v.26, p.704-728, 2005.

KIENLE; R.D. et al. Biplane transesophageal echocardiography in the normal cat. Veterinary Radiology \& Ultrasound, v.38, p.288-298, 1997.
KOFFAS, H. et al. Pulsed tissue Doppler imaging in normal cats and cats with hypertrophic cardiomiopathy. Journal of Veterinary Internal Medicine, v.20, p.65-77, 2006. Available from: <http://www3.interscience.wiley.com/cgi-bin/ fulltext/119820306/PDFSTART>. Acessed: Jun 03, 2010. doi: 10.1111/j.1939-1676.2006.tb02825.x.

KUNG, A.W.; NG, F. A rat model of thyroid hormone-induced bone loss: effect of antiresorptive agents on regional bone density and osteocalcin gene expression. Thyroid, v.4, p.9398, 1994.

MACDONALD, K.A. et al. Tissue Doppler imaging in Maine Coon cats with a mutation of myosin binding protein $\mathrm{C}$ with or without hypertrophy. Journal of Veterinary Internal Medicine, v.2, p.232-237, 2007.

MOONEY C.T. Hyperthyroidism. In: ETTINGER, S.J.; FELDMAN, E.C. (Eds.). Textbook of veterinary internal medicine. 6.ed. St. Louis: Elsevier Saunders, 2005. V.2, p. $1544-1560$

NAGUEH, S.F. et al. Doppler tissue imaging: A noninvasive technique for evaluation of left ventricular relaxation and estimation of filling pressures. Journal of the American College of Cardiology, v.30, p.1527-1533, 1997.

PETERSON, M.E. Diagnostic tests for hyperthyroidism in cats. Clinical Techniques in Small Animal Practice, v.21, p.2-9, 2006. Available from: <http://www.journals.elsevierhealth.com/ periodicals/ysvms/article/PIIS1096286705000770/fulltext>. Acessed: May 02, 2010. doi: 10.1053/j.ctsap.2005.12.001.

SHAN, K. et al. Relation of tissue Doppler derived myocardial velocities to myocardial structure and beta-adrenergic receptor density in humans. Journal of the American College of Cardiology, v.36, p.891-896, 2000.

SIMPSON, K.E. et al. Pulsed-wave Doppler tissue imaging velocities in normal geriatric cats and geriatric cats with primary or systemic diseases linked to specific cardiomyopathies in humans, and the influence of age and heart rate upon these velocities. Journal of Feline Medicine and Surgery, v.11, p.293-304, 2009.

SMIT, J.W. et al. Reversible diastolic dysfunction after longterm exogenous subclinical hyperthyroidism: a randomized, placebo controlled study. Journal of Clinical Endocrinology \& Metabolism, v.90, p.6041-6047, 2005.

SOHN, D.W. et al. Assessment of mitral annulus velocity by Doppler tissue imaging in the evaluation of left ventricular diastolic function. Journal of the American College of Cardiology, v.30, p.474-480, 1997.

SYME, H.M. Cardiovascular and renal manifestations of hyperthyroidism. Veterinary Clinics of North America Small Animal Practice, v.37, p.723-743, 2007. Available from: $<$ http://www.vetsmall.theclinics.com/article/ PIIS0195561607000654/fulltext>. Acessed: Jun 19, 2010. doi: 10.1016/j.cvsm.2007.05.011. 